\title{
Convergence theorems for fixed point iterative methods defined as admissible perturbations of a nonlinear operator
}

\section{VASILE BERINDE}

\begin{abstract}
.
The aim of this paper is to prove some convergence theorems for a general fixed point iterative method defined by means of the new concept of admissible perturbation of a nonlinear operator, introduced in [Rus, I. A., An abstract point of view on iterative approximation of fixed points, Fixed Point Theory 13 (2012), No. 1, 179-192]. The obtained convergence theorems extend and unify some fundamental results in the iterative approximation of fixed points due to Petryshyn [Petryshyn, W. V., Construction of fixed points of demicompact mappings in Hilbert space, J. Math. Anal. Appl. 14 (1966), 276-284] and Browder and Petryshyn [Browder, F. E. and Petryshyn, W. V., Construction of fixed points of nonlinear mappings in Hilbert space, J. Math. Anal. Appl. 20 (1967), No. 2, 197-228].
\end{abstract}

Department of Mathematics AND COMPUter SCiEnCE

NORTH UNIVERSITY OF BAIA MARE

VICTORIEI 76, 430122 BAIA MARE, ROMANIA

E-mail address: vberinde@ubm.ro

Received: 30.10.2011; In revised form: 22.09.2012; Accepted: 13.11.2012

2010 Mathematics Subject Classification. 47H09, 47H10, 54H25.

Key words and phrases. Hilbert space, nonexpansive operator, fixed point, Krasnoselskij iteration, admissible perturbation, demicompact operator, condition $(C)$, affine Lipschitzian operator, convergence theorem. 